\title{
Dynamic study on evolution mechanism of continuous innovation in prefabricated building enterprises
}

\author{
Yingdong Ji, Yue Yang ${ }^{*}$, and Wenting Ma \\ School of Management Science and Engineering, Shanxi University of Finance and Economics, \\ Taiyuan 030000, China
}

\begin{abstract}
As a new type of green building, prefabricated building is of great significance to sustainable development. In order to promote the innovation of prefabricated construction enterprises more smoothly, this paper obtains the data of 30 enterprises by issuing questionnaires and collecting public annual reports, and then uses the system dynamics model to simulate. The conclusions are as follows: technological innovation leads the development of enterprises. Market innovation and management innovation act on the growth period, organizational innovation act on the maturity period, and finally enters the period of continuous innovation to carry out collaborative innovation. Government support can effectively promote the development of prefabricated buildings. This study present suggestions for the innovation development of prefabricated construction enterprises, and provides reference for the sustainable development of national ecology and construction industry enterprise innovation.
\end{abstract}

Keywords: prefabricated building; sustainable development; system dynamics.

\section{Introduction}

The sustainable development of society and nature has increasingly become a key concern of the national society. In the field of architecture, greening of the construction industry is a new trend in recent years. As a new form of green building, prefabricated building is of great significance to sustainable development[1]. Especially during the COVID-19 pandemic, the construction of temporary hospital shows the development potential of prefabricated buildings. Compared with traditional buildings, the most prominent characteristics of prefabricated buildings are short construction period, low cost and green construction[2]. It effectively improves the huge environmental pollution problems caused by traditional buildings, which promotes the sustainable development of the construction field[3].

Prefab construction enterprises also have a 1 of difficulties in the process of innovation. First, Prefab construction requires a certain scale, a small scale will increase costs and lead to low market acceptance. Second, The scale of the construction base means that a one-time

*Corresponding author: yy041201@163.com 
high investment is needed, which increases the risk index correspondingly. The third is the high requirements for technology and management. Prefabricated building requires strict control of parts quality, prefabricated component quality and field operation[4]. Therefore, combined with the characteristics of different stages of enterprise growth cycle, this paper uses the system dynamics method to establish an analysis model, and draws a conclusion through simulation. Finally, it will guide enterprises to take targeted actions to make the construction industry reform smoothly. To a certain extent, this paper supplements the theoretical literature research in the field of prefabricated architecture, and promotes the sustainable development of the field of architecture.

\section{The innovation growth and evolution process of prefabricated construction enterprises}

The evolution mechanism of the innovation of prefabricated construction enterprises is a process in which the self-organization of the internal self-regulation of the system and the other organization of the government's macro-control function at the same time[5,6]. On the basis of interaction, each factor produces the comprehensive effect of the enterprise innovation evolution process, and guides the enterprise into the normal development track.

Combining with the growth track of enterprises, the growth process of prefabricated buildings can be classified into four stages: the start-up stage, the growth stage, the maturity stage and the continuous innovation stage[7]. In the initial stage, Technological innovation is the key to the growth of enterprises. The difficulties in this stage are mainly survival problems. The technology of prefabricated construction enterprises is not mature enough, which may lead to various forms of resource waste, which will affect the development of prefabricated buildings. With the end of the initial period, the market share of leading products has begun to expand[8]. Market innovation and management innovation play a significant role in this period. In the late stage of growth, the convergence of the assembly building mode is aggravating and the competition will become increasingly fierce. At this stage, improving the dynamic strategic adjustment ability of enterprises and exploring new profit growth points have become the focus. When the enterprise enters the mature stage, the internal organization system of prefabricated building develops more perfect. organizational innovation mainly plays a role in the period. Prefabricated construction enterprises timely update resources deploy, so that enterprises can always actively carry out the next development period. With the support of BIM Technology, In the continuous innovation period, enterprises enter into comprehensive collaborative innovation.

\section{Model construction and simulation analysis}

\subsection{Model construction and variable selection}

Based on the summary of previous studies, this paper constructs the causality diagram of system dynamics, as shown in Fig 1. It Shows the evolution process of prefabricated construction related enterprises. Then on this basis, the main simulation parameters are set, and the system dynamics flow chart is constructed, as shown in Fig 2. From the figure, we can see the interaction effect of various factors in the enterprise [9]. 


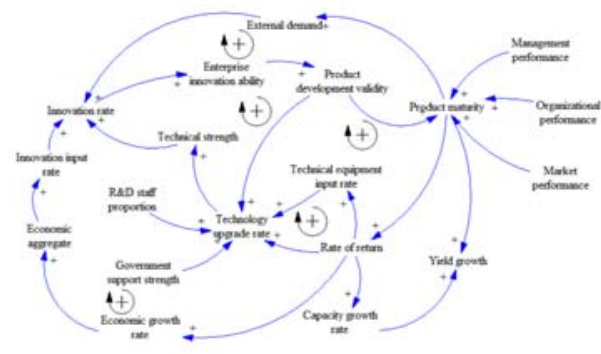

Fig. 1. Model causality diagram.

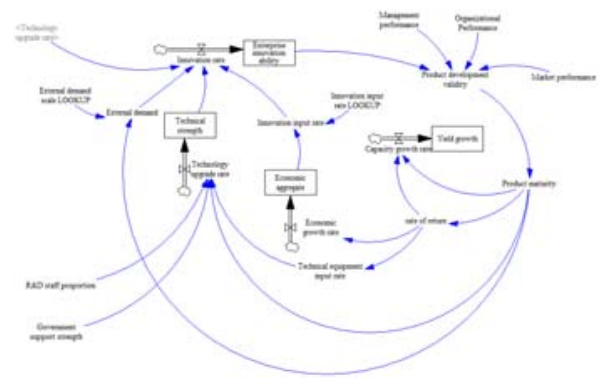

Fig. 2. The system dynamics flow chart.

We selected 30 enterprises as the research objects, The required data can be obtained by issuing questionnaires, inquiring patent data of assembly industry, data of listed companies, collecting company's public annual report on the Internet and interviewing. Table function data of external demand and innovation input rate are obtained through interviews and questionnaires, The proportion of R\&D staff is $5 \%$ of the total staff[10].

\subsection{Analysis of enterprise technical ability and overall economic strength}

After testing the validity of the model, we compared the coordinated development relationship between technology promotion rate and innovation investment rate under different states[11,12]. Software Vensim is used to simulate the innovation evolution process in the growth process of enterprises. Scenario parameters are set as follows: In the initial state (current), government support $=0.2$, management performance $=0.4$, market performance $=0.4$, organizational performance $=0.5$; Plan 1 : Keep other variables unchanged and increase government support from 0.2 to 0.5 ; Plan 2: management performance from 0.4 to 0.7 ; Plan 3 : market performance from 0.4 to 0.7 ; Plan 4 : organizational performance from 0.5 to 0.8 .

We analyze the technical ability and the overall economic strength of the enterprise. The coordinated development relationship between technology improvement rate and innovation input rate under different states is compared by changing the government support intensity and the parameters of management performance and market performance, as shown in Fig 3. The first graph is the original state, and the second graph is the state after adopting the Plan 2.
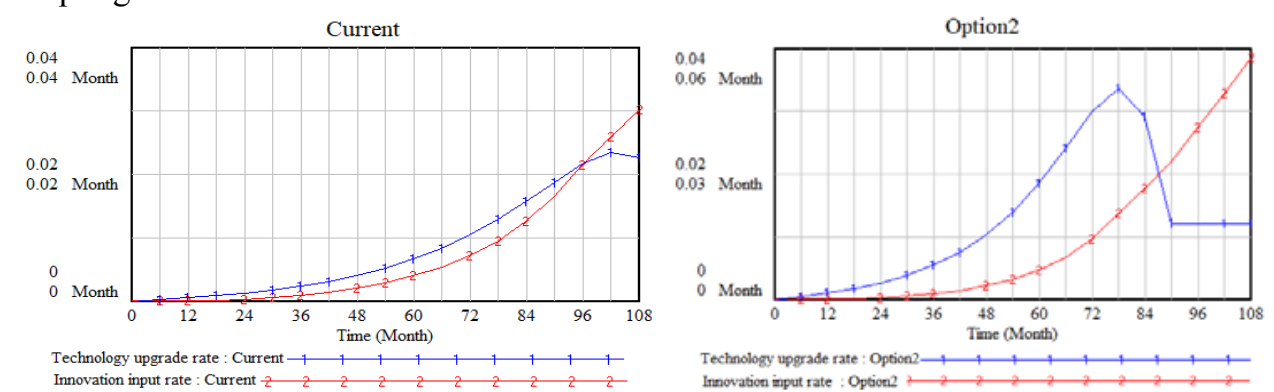

Fig. 3. Coordination between technology and economy

We can see from the figure that the relationship between technology promotion rate and innovation input rate is synchronous growth, When the enterprise development enters the mature stage (about 50 months), the management innovation and market innovation of the enterprise can promote the speed of technology improvement. When enterprise in maturity (80 months), the continuous investment in management and market innovation will lead to 
a decline in the innovation investment rate. At this time, technology and economy are no longer in a state of coordinated development (as shown in plan 2), Only by timely promoting the investment in technological innovation can the enterprises return to the track of sustainable and healthy development.

\subsection{The relationship between innovation and the growth of enterprises}

Taking the government support as external factors, management innovation, market innovation and organizational innovation as internal performance, the influence on the growth of prefabricated construction enterprises is shown in Fig 4 and 5.

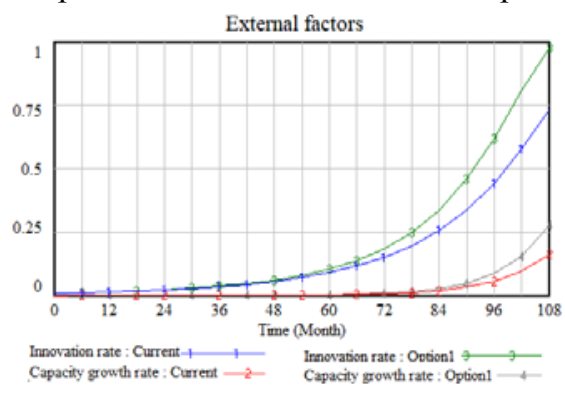

Fig. 4. External factors.

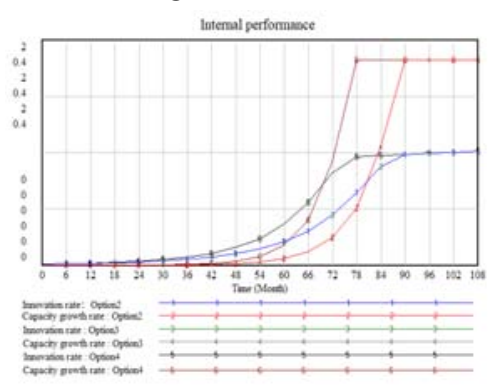

Fig. 5. Internal Performance.

We can see from Fig 4, the external factor has a certain impact on the whole evolution stage. We can found in Fig 5 that management innovation and market innovation play an important role in the growth period (about 30 months), The innovation rate and capacity growth rate rose rapidly and then stagnated, which indicated that further innovation behavior was needed. It also proves that technological innovation plays an important role in the initial stage. After organizational innovation, the innovation rate and productivity growth rate of enterprises increase exponentially, It shows that organizational innovation has a driving effect. In conclusion, there is always a positive correlation between innovation and enterprise growth. In each stage of enterprise development, the promotion effect of innovation on enterprise growth is always efficient, and small improvement of innovation ability can promote enterprise to have more obvious growth.

\section{Conclusions}

Combined with the results of simulation, the conclusions and suggestions can be drawn: First, In the continuous innovation period, innovation investment is positively correlated with enterprise development, management innovation and market innovation have an impact on the technological innovation rate in the later stage of development, At this time, if we can't estimate the relationship between product and innovation investment correctly, it will lead to the decline of innovation investment rate[13]. Therefore, We should establish a platform for the whole industry chain of assembly construction, promote the research of key technologies, and maintain the trend of coordinated development of technology and economy. Second, Through the simulation of innovation rate and capacity growth rate of different schemes, We can found that the importance of various schemes are different in different stages[14]. Therefore, it is necessary to invest resources in accordance with the development status of enterprises. Third, The government's increasing support for prefabricated construction enterprises can improve the overall innovation level and economic development speed of enterprises to a certain extent. Therefore, enterprises should seize the opportunity and enhance their independent innovation ability[15]. 
This paper studies the development of prefabricated construction enterprises from the perspective of life cycle, which is an innovation of previous research, it also makes a reasonable strategy for the development of enterprises, and has a reference significance for the subsequent development of enterprises.

\section{References}

1. Q. Liang, Discussion on sustainable development of building economy. International public relations 04, 196-198 (2020)

2. B. Li, The present situation and development of prefabricated buildings in China. China Science and Technology Information 07, 114-115 (2014)

3. Y.L. Deng, J.Y. Li, Q.T. Wu, S.S. Pei, N. Xu, G.D. Ni, Using Network Theory to Explore BIM Application Barriers for BIM Sustainable Development in China. Sustainability 12(8) (2020)

4. K.M.A. El-Abidi, G. Ofori, S.A.S. Zakaria, Using Prefabricated Building to Address Housing Needs in Libya: A Study based on Local Expert Perspectives. Arabian Journal for Science and Engineering 44(10), 8289-8304 (2019)

5. Y.Z. Bai, Y. Zhang, Y. Xue, The growth process of social Enterprise and its Selforganization Evolution Mechanism -- A Study from the perspective of entrepreneurial ecosystem. Scientific and technological progress and countermeasures 4, 84-89 (2017)

6. H. Ernst, U. Lichtenthaler, C. Vogt, The impact of accumulating and reactivating technological experience on R\&D alliance performance. Journal of Management Studies 48(6), 1194-1216 (2011)

7. J.G. Li, B.X. Li, Stage characteristics and Simulation of innovation evolution in the growth process of innovation-oriented enterprises. Operation and management 3, 227233 (2015)

8. N. Stieglitz, K. Heine, Innovations and the role of complementarities in a strategic theory of the firm. Strategic Management Journal 28(1), 1-15 (2007)

9. Y.J. Yuan, Y. Tian, J. Sun, System Dynamics modeling and Simulation of stability of industry-University-Research Technology Alliance. Science and management of science and technology 4, 3-9 (2014)

10. L.T. Chen, Q.R. Xu, Z.Y. Wu, Strategic Vision, Innovation Search and Technological Innovation Capability Evolution--Theoretical Modeling and Simulation Research based on System Dynamics. System engineering theory and practice 34(7), 1705-1719 (2014)

11. Q. Pi, X.L. Wang, L. Zhang, Research on influencing factors of urban energy carrying Capacity based on SD model. Statistics and Decision 4, 109-112 (2016)

12. H. Cheng, J.X. Wang, D.Q. Li, System Dynamics Model Simulation of Regional Technology Innovation and Economic Growth based on research in Zhejiang Province. Science and Technology Management Research 10, 93-96 (2015)

13. B.R. Qu, A Simulation study of prefabricated Building Policy in Nanjing Based on System Dynamics. Beijing Jiaotong University (2019)

14. B.R. Qu, A Simulation study of prefabricated Building Policy in Nanjing Based on System Dynamics. Beijing Jiaotong University (2019)

15. C. Bao, D. He, Scenario Modeling of Urbanization Development and Water Scarcity Based on System Dynamics: A Case Study of Beijing-Tianjin-Hebei Urban Agglomeration, China. Int. J. Environ. Res. Public Health 16, 3834 (2019) 